\title{
1. Towards a discursive research agenda for organizational psychology
}

\author{
Patrizia Hoyer, Chris Steyaert and \\ Julia C. Nentwich
}

No genuinely critical work can emerge from within psychology that does not scrutinize the disciplinary location from which it emerges. (Hook, 2007, p. 3)

\section{INTRODUCTION}

The purpose of this book is to introduce and illustrate a multiplicity of discursive approaches applied to a range of classical and newer organizational themes in the field of organizational psychology (OP). By creating continuity within a given research tradition and also exploring new directions, the book is designed for a range of audiences. It may serve as a guide for researchers who are new to discourse analysis in the field of organization and management studies and who would like to learn about discursive approaches inspired by discursive psychology and investigate OP themes from a discursive angle. At the same time the book may serve as a starting point for those organizational psychologists familiar with the discipline, but less familiar with the epistemological and methodological underpinnings, and the empirical challenges, which offer plenty of chances for scholars in OP to generate various questions and perspectives. It might provide inspirational reading for scholars already contemplating or even conducting discourse analytical research in the field of organization studies/OP and for those who would like to enhance their conceptual and/ or methodological understanding of it and critically reflect upon the discursive inquiry of organizational phenomena. Finally, this book addresses the broader community of organizational scholars (some of them quietly holding a degree in OP) as it draws attention to a number of discursive studies which clearly address OP themes, but have thus far often had to find 'a home' in the broader arena of organization studies, as the discipline of OP has been rather slow to embrace discursive approaches. 
With the aim of suggesting such an agenda, we have broadly divided this first, introductory chapter into two parts. In the first part we briefly introduce the more general emergence of discourse analysis in the study of organizational phenomena, and then review how discourse analysis has been applied to date in analysing OP themes. We show how this emergence is aligned with several historically situated waves of psychology which have shown various levels of openness to discursive approaches to organizational phenomena. In the second part, we highlight the core contributions which the family of discourse methods brings to our understanding of OP topics, and also indicate key areas of debate that may pose challenges to the field but also set the direction and scope for its future research trajectory. In speculating on emerging trends and reflecting upon new developments, we try to sketch out how discourse analysis may become a key element in launching a consistent and substantial research agenda in the field of OP.

\section{TRACING THE OPENINGS FOR A DISCURSIVE ORGANIZATIONAL PSYCHOLOGY}

\section{The Linguistic Turn in Organization Studies}

The upsurge of interest in discursive approaches may have occurred as organizational scholars became disillusioned with a number of mainstream theories and methodologies (Grant, Hardy, Oswick and Putnam, 2004). As these scholars attempted to move beyond modernist and univocal accounts in the study of complex organizational processes (Oswick, Grant, Marshak and Wolfram-Cox, 2010), 'organizational discourse' emerged with a new terminology that invited alternative understandings of organizational and inter-organizational phenomena (Iedema, 2011). With the 'linguistic turn' in the 1980s (Deetz, 2003), a new perspective on the relationship between language and reality was introduced to the social sciences (Alvesson and Kärreman, 2000). This new perspective was grounded in the (meta-)theoretical assumption that language is constitutive of social reality (Grant et al., 2004).

The epistemological postulation of the discourse project, however, signified much more than a simple shift in attention to matters of language. It became a shorthand for an entire philosophical tradition influenced by scholars such as Wittgenstein, Barthes, Foucault and Derrida (Mumby, 2011). Traditionally, language was considered to be a passive descriptor of pre-existing objects - it was 'true' when it correctly reflected reality and 'false' when it did not - but the 'linguistic turn' marked a radical departure from the view that language simply mirrored or revealed a pre-existing 
social reality (Phillips and Oswick, 2012). Instead, it suggested that, through the production and dissemination of text and talk (Berger and Luckmann, 1967), or more concretely, in the process of 'differentiating, fixing, naming, labeling, classifying and relating' (Chia, 2000, p. 513), discourse may construct whatever phenomenon we are interested in. This new insight greatly unsettled the conventional wisdom of language as being unproblematic (Alvesson and Kärreman, 2011a).

The linguistic turn took some time to find its way into the study of organizations, but eventually organizational discourse became a prominent area of analysis (Leclercq-Vandelannoitte, 2011). As they employed a social constructionist epistemology (see Chapter 2), researchers became sensitized to the discursive dynamics that were also pertinent in the construction of organizational reality. Now that organizations were no longer considered as objects to be counted and measured (Phillips and Oswick, 2012), discourse analysis opened up possibilities for re-imagining the everyday practices of organizing in a processual way. As discourse analysis took a particular interest in how texts became meaningful in relation to other texts, and how collections of texts could affect the social context in which they occurred, close attention was given to organizational discourses that defined what was to be considered as normal, acceptable and standard behaviour, thereby reproducing and institutionalizing certain practices (Hardy and Maguire, 2010).

Hence, by recovering the intrinsically political nature of discourses that may privilege one reality construction over another, organizational discourse studies problematized power relations and conceptualized organizations in performative terms, bringing issues of knowledge, power and resistance to the core of organizational analysis (Phillips and Oswick, 2012). As they engaged in interpretation and deconstruction, scholars began to realize how much routine organizational interactions were taken for granted; they also saw how discursive closure was being reified in the form of marginalization or naturalization (Mumby, 2011). At the same time discourse provided the means to point out that things could also be different, thereby exposing the effects of acculturation and habituation (Iedema, 2011) and even inviting competing discourses that held the potential for bringing about institutional change (Hardy and Maguire, 2010). Built on these premises, organizational discourse inspired a variety of analytical and interpretive moves that were considered particularly suitable for studying the complexity and processuality of organizational phenomena (Alvesson and Kärreman, 2011a; Chia, 2000).

Whereas other qualitative approaches were tailored towards understanding and revealing organizational reality, discourse analysis investigated how language constructed the experience of reality in the first place 
(Phillips and Oswick, 2012). In particular, this discursive conception of reality brought with it practical implications for researchers' methodological choices about the way they would identify, collect and analyse data (Phillips and di Domenico, 2009). Over the past two decades then, organizational discourse expanded into such a well-established theoretical and methodological framework for organizational analysis that the continued proliferation of discursive studies turned it into a veritable 'shooting star'; it quickly became 'a mainstream, conventional, institutionalized and (almost) canonical "field" of study' (Rhodes, 2005, p. 793), granted space for special issues even in top tier journals (Phillips and di Domenico, 2009; Phillips and Oswick, 2012). For instance, Grant et al. (2004, p. 1) could claim that '[it] is now difficult to open a management or organizational journal without finding that it contains some sort of discursive-based study'. In fact, many books, special journal issues, edited collections and even conferences - such as the international conference on organizational discourse, meeting biannually since 1994 - have been dedicated to the topic of discourse and discursive studies in the field.

\section{The Stalemate in (Organizational) Psychology}

Though discourse studies have generally been gaining prominence in the social sciences, discursive work in the more specific field of organizational psychology has received little attention to date. As many scholars within the field of OP have moved their locus of commitment and publication to other so-called 'neighbouring fields' such as organization studies and critical management studies, few have noticed the potential in the contributions that organizational psychologists have made to these seemingly expansive and all-encompassing fields. This is particularly pertinent since OP has provided widely applied and popularized concepts that up to now shape organizational discourses and practices. Indeed, our starting point is the considerable impact of work and organizational psychology, as many of its concepts have come to centre stage in both everyday discourse and professional language since its conception in the early 20th century.

The application of psychological notions to the field of work and organization has had a great impact, as the language of psychology has considerably shaped the discourse of corporate selfhood: 'The psychological discourse was enormously successful because in the background of the rise of the professions, psychologists offered a language - of persons, emotions, motivations - which seemed to correspond to and make sense of the large-scale transformations of the American workplace' (Illouz, 2007, pp. 16-17). Thus, OP notions such as intelligence, personality, identity and motivation, as well as practices like collaboration, participation, coaching 
and teambuilding, have travelled and become part of organizational theory and practice. To understand how psychology in general and organizational psychology in particular have allowed for a discursive investigation of these topics, as this book tries to illustrate, we will first take note of a number of alternative positions which have developed within these fields.

A key reason psychology has been such a successful discipline is that its ideas, concepts and practices have had a widespread impact on all parts of society, including work, education, health care, sexuality, family, criminality, and security. As psychological concepts and practices were adopted in everyday life and found widespread application during the 20th century, psychology 'prospered by becoming a protean profession, responsive to the needs of any and all' (Capshew, 1999, p. 264). Driven by the demands of the marketplace, Capshew explains, '[p]sychological knowledge became a cultural commodity that was easily manufactured and widely distributed by a self-sustaining community of technoscientific professionals'.

This increasing success, however, brought with it mounting scrutiny, analysis and critique. Ironically, psychology became a discipline in search of its self. Since the early seventies the discipline of psychology has received strong critiques both from inside its own community and from external analysts. Within the discipline, various alternative strands were developed in the interpretive (Held, 2007; Tappan, 1997), critical (Fox and Prilleltensky, 1997; Fox, Prilleltensky and Austin, 2009; Hepburn, 2003), social constructionist (Burr, 2003; Gergen, 1985) and feminist (Burman, 1998; Gergen, 2001a; 2001b; 2010; Wilkinson, 1986; Wilkinson and Kitzinger, 1996) psychological approaches. Psychology was criticized for its one-dimensional attachment to neo-positivist scientific models and for celebrating the methods and logics of the natural sciences. Even though the narrowly defined and positivist boundaries had expanded over the years, the 'traditional' discipline of psychology continued to be strongly associated with theories and methods that systematically excluded nonquantitative perspectives (Weatherall, 2012). Moreover, psychology was criticized for failing to consider ideological and political differences, and even for reproducing them, and for imperialistically imposing a heroic and phallocratic individualism on people and cultures across the world (Gergen and Davis, 1996).

From the outside, but not independent of these internal comments, psychology tried, but failed, to stay out of the interpretive, critical and poststructuralist upheavals in the human and social sciences since the late sixties. Multiple approaches - Habermas' analysis of interests in knowledge-seeking, Foucault's understanding of the power/knowledge nexus in the construction of our ideas and identities, and Derrida's deconstruction to analyse binaries and to reveal contradiction and suppressions 
of meaning - scrutinized and questioned the ways the psychological discipline proceeded in scientific knowledge production and in authoring all things called psychological problems and interventions in society at large (Hepburn, 2003).

Psychology did no longer 'count' as a neutral scientific endeavour; rather, it became clear, as Hook explained (Hook, 2007, p. viii), that 'both through its practices and through the concepts that justify its practices', psychology 'operates for the most part as an ideological apparatus'. As a result, 'its array of discourses and activities constructs and sustains systems of domination and oppression even as they appear to support self-understanding and well-being'. As they operate, '[t]herapy, counseling, assessment, research, self-help, prevention work, clinic spaces, case studies and all forms of psy-work construct specific forms of understanding and experience'. In light of this growing critique, some psychologists did try to enter new premises by developing alternative perspectives and approaches, thereby, reinventing themselves. In the following section we will draw particular attention to the rise of discursive psychology.

\section{The Entry of Discursive Psychology}

Discursive psychology - as it explored the possibilities of discourse theory to analyse psychological phenomena - was based on a critique of the old paradigm, in which psychology rarely included itself in the phenomena that it described. Instead, it preferred to study those outside the discipline by promoting an abstract model of behavioural and cognitive mechanisms that was in line with the rigid methodologies employed for studying them (Parker, 2012). So, not long after the 'crisis in social psychology' during the 1970s, discursive psychology emerged in the late 1980s and early 1990s as a promising and dynamic new enterprise that did not simply provide another critique, but instead offered an alternative to social psychology, one that was both theoretically and methodologically coherent. Given social psychology's fetishism for experimentation, this may be considered a revolutionary turn (Augoustinos and Tileagă, 2012); indeed, it has been the centre of many controversial debates (Stokoe, Hepburn and Antaki, 2012).

In seeking out the intellectual and historical origins of the discursive project in social psychology, three seminal books - all published in 1987 were said to actually predate the establishment of the term 'discursive psychology' (Augoustinos and Tileagă, 2012). These books all mark a critical body of work on language and social psychology; they are Discourse and Social Psychology by Jonathan Potter and Margaret Wetherell, Common Knowledge by Derek Edwards and Neil Mercer, and Arguing and Thinking by Michael Billig. Some scholars see the intersection between these three 
books as the birthplace of discursive psychology. Though other accounts on the rise of discursive psychology do not view all three books as equally significant (Billig, 2012), there is a wider agreement that the Potter and Wetherell book, cited over 4,000 times in over 250 different journals, has had a major impact across various social and human sciences (Potter, 2012).

Much of the success of Discourse and Social Psychology may be attributed to its setting out a clear and detailed vision of how research might be done (Potter, 2012) in terms of a systematic, empirical analysis of everyday recorded talk (Edwards, 2012). Especially by introducing and drawing on 'interpretative repertoires', which became a central tool for analysis, the authors investigated how people employed common-sense descriptions as rhetorical resources for explaining and preserving moral and social orders (see also Weatherall, 2012).

Content-wise, discursive psychology took the topics of the social psychology textbooks of that time (Potter, 2012) - attitudes, cognition, attribution, persuasion, identity, prejudice, and so on - and offered alternative ways to analyse these topics as they were produced in formal or informal everyday talk (Augoustinos and Tileagă, 2012). In this way discursive psychology offered an alternative perspective for apprehending the mutual relationship between people, practices, and institutions; it also introduced a coherent set of concepts and methods for investigating these relationships (Augoustinos and Tileagă, 2012).

When considering its development over the past few decades, however, critics have argued that discursive psychology is no longer driven by its initial political impetus to unsettle the disciplinary concerns and practices of mainstream psychology, as it now makes few, if any, critical references to other kinds of psychology (Billig, 2012; Edwards, 2012; Parker, 2012). Instead, by working in partnership with the mainstream, discursive psychology has become a distinct and popular 'way of doing psychology'. Based on this harmonization, Stokoe et al. (2012) have even accused the field of having lost its critical edge for engaging in emancipatory projects and for potentially bringing about social change.

Despite these objections, there remains little doubt that discursive psychology has made a considerable contribution in terms of redefining social psychology and other areas (Dickerson, 2012; Van Dijk, 2012). This 'new field' within psychology has generated a considerable network of scholars who by now identify as 'discursive psychologists' with a growing number of postgraduates who engage in this type of work (Augoustinos and Tileagă, 2012), and a wealth of introductory textbooks to this new psychology (for example, Burr, 2003, 2015; Dickerson, 2012; Hepburn, 2003; Tuffin, 2004). This achievement of discursive social psychology is not to be underestimated, given that it moved from being at the margins of 
'politically motivated critique' to now sit comfortably within the tradition of western psychology (Augoustinos and Tileagă, 2012).

\section{The Potential for a Discursive Research Agenda in Organizational Psychology}

In contrast to the noteworthy development of discursive approaches in (social) psychology, quite a different story must be told for the neighbouring field of organizational psychology. First of all, OP has not been considered a stable arena as it has continuously been evolving. In fact, OP is rarely seen as its own field; it is usually presented in connection with personnel psychology (Steffy and Grimes, 1992), industrial psychology (Islam and Zyphur, 2009) or work psychology (Chmiel, 2008), which blurs its boundaries and obscures its actual contributions. Second, and in contrast to some other social sciences, the canon of theories, methodologies and methods that constitute this subfield of psychology have been rather static, as one can see by comparing its textbooks over the years. As a consequence, many of the OP scholars who take a more critical approach have shifted their focus to the wider field of organization studies. That field, 'which is distinct from, but in many ways parallel to, IO psychology, has a rich and growing critical and postmodern tradition ... but has been more strongly represented in business schools and in sociology departments than in IO psychology departments' (Islam and Zyphur, 2009, p. 122). It is not surprising then that much of the OP research to date continues to be highly interdisciplinary and aligned with research in the areas of sociology and management (Parker, 2012).

OP's lack of critical and reflexive engagement with its own research processes, which encompassed neither neutral nor innocent activities of knowledge and reality productions, has triggered a growing series of critical analyses and attempts to reframe its research agenda. For example, in a critical review of personnel and organizational psychology, Steffy and Grimes (1992) retraced the self-regulating code of discourse which constitutes the discipline. In describing the set of rules that reflect its ontological content, epistemological strategy and methodological tactics, they observed that "psychology in general and [P]OP in particular have not witnessed the schisms and debates that characterize other organizational and social sciences' (Steffy and Grimes, 1992, p. 183). As ontological and epistemological questions were mostly assumed to be irrelevant in the neo-positivist approaches of OP, self-critique and reflection have thus far been mostly limited to considering whether researchers have adequately followed the normative rules of method and proper validation procedures.

Drawing upon the work of Habermas and Foucault, Steffy and Grimes 
(1992) called for a critical research agenda that would imply greater reflexivity in knowledge production. Wendy Hollway (1991) took this initiative a step further in what is by now almost a classic: Work Psychology and Organizational Behaviour. Hollway reframed 80 years of history of work psychology based on the perspectives of Althusser and Foucault. Her analysis showed that the research in OP has mostly been tied to the goals of regulation by management, but she pleaded for research that would focus on the 'multiple and competing discourses which contribute to people's positioning' (Hollway, 1991, p. 188).

In response to these criticisms, one aim of our book is to retrace some lines of OP and to re-invigorate and make visible its specific contributions to the field of organizational studies. At the same time we aim to connect to the critical tradition of studying how psychological concepts and practices are enacted in organizational contexts. Moreover, by drawing on multiple logics of organizing and reflecting upon the paradoxical ways in which these logics become maintained or changed in research processes, this book aims to draw attention to more innovative developments in OP that have so far remained dispersed and thus not noticed in the wider field of organization studies.

Consequently, with the current book we draw attention to the discursive analysis of classical as well as crucial themes in OP. By doing so we place into perspective OP's potential - thus far mostly neglected - to contribute to the broader discursive movement in organization studies. In that way, the book follows one important line of research: tracing how discursive studies can be established as a different form of analysis in OP, one that presents and reflects upon its own performance in the course of studying a broad range of research topics. Discursive endeavours in OP mark a noticeable development of distinct forms of studying and explaining language based on taking up discourse-analytical, rhetorical and deconstructionist ways of proceeding. In the following section we delineate what a more explicit discursive agenda in the field of OP could possibly look like.

\section{DISCOURSE ANALYSIS IN OP: CHALLENGES, DEBATES AND FUTURE POTENTIALS}

When they look ahead, organizational scholars still expect to see growth in discourse oriented work (Oswick et al., 2010); they argue that the potential scope for its application has not yet been realized (Grant et al., 2004). As we have tried to maintain in this introductory chapter, this expectation for growth is particularly apposite for discursive studies in the field of OP; we believe a substantial research agenda for discursive contributions could 
soon gain considerable momentum. Despite this optimism for such an agenda, we are also quite aware of current challenges and debates around the discourse project which can certainly create obstacles to further establishing a discursive research trajectory in OP. Thus we also address some of the future potentials - along with these challenges and debates - for further opening up the field of discourse studies, thereby turning the call for discursive work in the area of OP into a more thought-provoking and daring venture.

Therefore, in the pages to come we address several issues of debate and concern. First, we look at the problem of broad definition, which renders 'discourse' and 'discourse analysis' as two loosely defined concepts that for better or worse have resulted in a huge variety of different research approaches over a vague common denominator. Second, and in line with this concern about the variety of approaches, we shed light on a debate around conceptual clarity and methodological rigour which has divided the community of scholars into proponents of more standardization and consistency on the one side and advocates for open, trans-disciplinary and multi-methodological analysis on the other. Third, we warn about overemphasizing and privileging language and discourse at the expense of other non-discursive elements such as materiality and affect that also mark important ingredients of organizational life and meaning making. In our closing thoughts we delineate how these challenges and debates may after all - inform rather than jeopardize the goal of strengthening the link between OP themes and discourse studies by making that link more explicit and thereby more prominent.

\section{Variety in Theories: Discourse Analysis as a Fuzzy Concept}

The first issue of debate revolves around the critique that 'discourse analysis', like the term 'discourse' itself, lacks a simple definition that clearly delineates its boundaries (Phillips and di Domenico, 2009; Phillips and Oswick, 2012). As a consequence, discourse analysis has been criticized for being a poorly defined, vague, ambiguous and fuzzy concept, encompassing a bewildering array of disparate perspectives, methods and approaches. As discourse may mean a broad range of different things, it may above all be considered an umbrella term that accommodates an enormous diversity of ways that people talk about and analyse organizational discourse (Grant et al., 2004).

Different academic disciplines have drawn on the term 'discourse analysis' to describe what they do and how they proceed to do it (Bargiela-Chiappini, 2011). This eclecticism may be explained by the way that organizational discourse analysis has evolved over time from an array 
of distinct disciplinary antecedents (Phillips and Oswick, 2012), including the traditions of sociology, anthropology, psychology, social theory, linguistics, sociolinguistics, communication and literary-based studies (Bargiela-Chiappini, 2011; Grant et al., 2004). For instance, intertextual analysis derives from the work of Bakhtin $(1981 ; 1986)$ and is grounded in literary studies, while Foucauldian discourse analysis, as the name suggests, emanates from Foucault's (1972; 1980; 1984) work, which itself was nested within philosophy, history and social theory (Phillips and Oswick, 2012). Alvesson and Kärreman (2011a), among other scholars, express their discontent with this variation, suggesting that it 'overpacks' the concept of discourse, makes it clumsy to use, clouds awareness of different theoretical and analytical options and thus leads to confusion. As they see it, the only thing that unites much discourse work is the (over)use of the discourse label. By not using this signifier in a nuanced way, they say, some researchers have applied it rather uncritically to cover up muddled thinking.

While other commentators share this critical view, seeing the varied use of organizational discourse analysis as problematic (Van Dijk, 1997), others in fact see it as a healthy sign of pluralism which serves as a source of strength and has the potential to be further exploited for meaningful contributions to the study of organizations (Grant et al., 2004; Phillips and Oswick, 2012). This is especially the case for scholars who, in a poststructuralist or processual mode of engagement, embrace concepts of multiplicity, plurivocality and paradoxicality; they subscribe to an understanding that there is never just one (understanding of) discourse that characterizes organizational life, but a multitude of relatively autonomous yet overlapping organizational discourses, each of which allows for a variety of possible readings. From this perspective, a given research endeavour provides only a limited appraisal of the multitude of 'organizational realities', depending on the conceptual perspective and the methodological choices that determine the study (Grant et al., 2004). Considering the organization itself as a fluid and polyphonic entity, several scholars try to avoid definite readings of discourses that would reify the concept 'organization' (Chia, 2000) and thereby exclude notions of incoherence and inconsistency. These notions are key however for understanding the escalating demands of globalization and the increasing unpredictability of markets (Grant et al., 2004).

In the course of suggesting a discursive research agenda in the field of OP, we go along with those who advocate for multiplicity and hospitality towards discursive approaches that have different disciplinary roots. Hence, in the chapters of this book you will find a varied mix of discursive endeavours - but what aligns them all is the idea that language 
(together with other social practices) constructs organizational reality. Many upcoming studies lean towards a discursive psychology approach, where concepts of interpretative repertoires and rhetorical arguments or strategies come to centre stage. Several others take an explicitly critical perspective that is influenced by the work of Habermas, Gramsci or Foucault, while still others draw on more recent debates and understandings, where discourse is framed for instance as 'practice' or 'intervention'. While allowing for such a broad understanding of discourse in the suggested research agenda in OP, we also emphasize the need to strive for conceptual clarity and transparency when conducting and writing up empirical studies. We have therefore encouraged the authors included in this book to be quite careful and explicit in demarcating the boundaries for their specific use and understanding of the term discourse. It is exactly this combination of multiplicity on the one hand, and definitional clarity on the other, that we find promising for a future research trajectory in the field of OP.

\section{Variety in Methods: Between Methodological Rigour and Flexibility}

Some see another 'problem' that goes along with the high degree of diversity and heterogeneity in the field: the variety of methods applied in discourse studies. This has led to a debate around conceptual clarity and methodological rigor, which is nicely exemplified in a point-counterpoint exchange between Leitch and Palmer (2010) on the one hand and Chouliaraki and Fairclough (2010) on the other (see also Antaki, Billig, Edwards and Potter, 2003). Leitch and Palmer have looked sceptically at the loose application of concepts and methods, particularly in the area of critical discourse analysis (CDA), but also in the broader field of discourse studies; they argue that the field needs at least some area of commonality underpinning a methodological approach. They fear that researchers may draw on CDA as a rhetorical sleight of hand, thereby omitting a detailed description of the methods they used in their analysis of discourse. Doing so could limit the inherent potential of discourse work, and it could mean that researchers are actually combining paradigmatic assumptions unreflexively. Hence, Leitch and Palmer (2010) make the case for more definitional clarity as well as for greater consistency and rigor in the methodological application of discourse analysis. They suggest nine 'methodological protocols' that can help researchers to systematically address three stages where they must decide on their methods: defining concepts, selecting data, and analysing data.

In contrast to that view, Chouliaraki and Fairclough (2010) have clear reservations about the ability of universal methodological protocols and rigid rules to guarantee consistency and regularity. They see such 
regulation, based on tight definitions and single protocols, as undesirable, as it puts limits on CDA as a methodology and thereby restrains the dialectical relations between discourse and other elements of 'the social'. Instead they argue for leaving analysis deliberately more flexible and even porous, so it can remain versatile and contingent on the specific research questions at hand. In that way, new space can be created for an alternative conception of discourse. Novel research designs in the field may then become transdisciplinary and integrationist, privileging a spectrum of desirable methodological variation over rigour (Bargiela-Chiappini, 2011; Chouliaraki and Fairclough, 2010).

We concur with the editors (2010) of this point-counterpoint debate who note that both Leitch and Palmer (2010) and Chouliaraki and Fairclough (2010) raise valid points. While the former are concerned with the dependability of discursive research, the latter are worried that an overemphasis on strict methods may make it harder for researchers to use discourse work flexibly in both theoretical and critical ways. Thus, to begin unfolding a discursive programme in OP we suggest keeping a fruitful balance between both positions. Rather than supporting strict adherence to predefined research protocols, we promote methodological variety and urge researchers to develop the flexible methodological approaches they believe are most appropriate for, and even tailored to, the characteristics of their area of interest and research questions. On the other hand we have urged the authors in this book to act as guides for their readers, and thus to be as explicit and detailed as possible when describing their empirical setup, their unit of discursive analysis, and the various steps they took during their analysis. In this way we have allowed for a broad variety of analytical approaches that are still transparent and unambiguous regarding their methodological choices.

\section{Expanding the Focus on Discourse: The Relevance of Materiality, Affect and Aesthetics}

The third issue we would like to draw attention to is a critique: with the widespread adhesion to a social constructionist epistemology, some organizational scholars have overvalued the significance of language, meanwhile not paying sufficient attention to other facets of organizational life (Bargiela-Chiappini, 2011). This critique addresses researchers who uncritically reproduce some taken-for-granted assumptions that underlie the discourse project (Bargiela-Chiappini, 2011). Within such a discourse-driven mindset, so the argument goes, organizational complexity has been converted into text, no questions asked (Iedema, 2011). When most activity in organizations is considered to be discursive in nature (Grant et al., 2004), 
there is little evident need to study anything 'outside' of discourse. This emphasis, some say, has greatly diminished the value of discourse analysis, which is not sensitive enough to non-linguistic aspects of organizing (Mumby, 2011) or misunderstood the materiality of discourse (Prasad, 2005; Hardy and Thomas, 2015).

In line with this argument, Robert Chia (2000), despite his passion for the social constructionist ontology, acknowledged that some areas of experience within organizations are not so easily captured in discursive endeavours (Bargiela-Chiappini, 2011). Critics of discourse have particularly flagged the topics of affect, aesthetics and other more embodied versions of sensemaking as being beyond the reach of textual analysis, and have called for different modes of engagement (Potter, 2012). Assuming that affect is continuous, pre-personal and pre-conscious (Anderson, 2014), researchers concerned with it tend to focus on movement, change and ephemeral action; meanwhile discourse is limited to dealing with experiences that are discontinuous, and capable of being located and owned. Addressing affect in a non-discursive way would make it possible, though, to study the not-yet-said, thereby engaging with phenomena that would otherwise be disdained as matters of intuition, suspicion, or magic. When they are simply ignored, however, these dimensions of embodied affect may undermine rather than enrich the project of discourse studies, and render it 'immaterial' to the contemporary study of organizations (Iedema, 2011). Hence, scholars with an interest in a 'post-linguistic turn perspective' (Mumby, 2011) would appreciate better ways to attend to the material, the physical, and the affective, as well as to the aesthetic qualities of work-related experiences (Bargiela-Chiappini, 2011; Kenny and Fotaki, 2012; Putnam, 2015). For instance, Margaret Wetherell (2012) has undertaken an encompassing attempt to align affective and discursive dimensions of practice; she called the affective turn the wrong turn because, as she observed, the discursive becomes almost entirely separated from conceptualizations of affect.

Rather than making a case for affect and materiality in replacing discourse, we have a different suggestion for a future research trajectory in OP: bring the interface between the discursive and the non-discursive into a meaningful balance (see also Alvesson and Kärreman, 2011a; 2011b; Wetherell, 2012; Putnam, 2015). Looking into the future, we believe that, if discourse analysis were explored to its full extent, it might reach its limits in terms of contributing new understandings. Hence it might be more farsighted to begin exploring some potentially fruitful methodological pairings that would combine discursive approaches with non-discursive ones; this would mean a shift from focusing only on linguistic methods to including methods that invite complementary understandings of organizational 
processes (Phillips and Oswick, 2012). Ethnography, as one example, may well have the potential to bring together text and context, that is, to combine discourse with the material, the nonverbal and the relational (Bargiela-Chiappini, 2011; Nentwich, 2014; Steyaert and Van Looy, 2010; Wetherell, 2007; Hardy and Thomas, 2015).

By concurrently applying discursive and non-discourse approaches and then eventually letting go of this unfruitful binary - the field of OP might be able to move beyond the discursive isolationism that has kept some neighbouring fields from developing multidisciplinary approaches and connecting to the more material world of organizations (Phillips and Oswick, 2012).

\section{CONCLUSION AND FUTURE OUTLOOK}

To date, strict 'gate-keeping' practices in the mainstream field of OP have forced researchers with an interest in discursive approaches to go outside of the discipline where critical and alternative perspectives are less marginalized, but considered relevant and hence more publishable. In this introductory chapter we have tried to sketch out a discursive research agenda that would allow OP studies that are so far widely dispersed in the broader field of organization studies to become more visible. Having said this, we are not necessarily suggesting that discourse analysis in OP 'become a coherent alternative tradition' (Parker and Burman, 2008, p. 102; see also Symon and Cassell, 2006). Instead, we would like to draw attention to discursive OP work as a complementary form of qualitative and critical inquiry; rather than becoming a new standalone approach we believe it enlightens the existing research project in OP and widens its scope.

Moreover, we call for a more conscious and daring engagement with some of the roots of OP themes that currently go unnoticed in the wider context of organization studies, where studies in the intersection between discourse work and OP topics are being published. Above all, we see the possible contribution that lies in developing a discursive research agenda in OP, a promising direction for future research that continues to open up new ways of exploring organizational psychological phenomena. In the next chapter we provide an overview of the chapters of this book; they illustrate ways to combine a range of (post-)discursive approaches with various OP themes and phenomena. 


\section{REFERENCES}

Alvesson, Mats and Dan Kärreman (2000), 'Taking the linguistic turn in organizational research: Challenges, responses, consequences', Journal of Applied Behavioral Science, 36 (2), 136-158.

Alvesson, Mats and Dan Kärreman (2011a), 'Decolonializing discourse: Critical reflections on organizational discourse analysis', Human Relations, 64 (9), 1121-1146.

Alvesson, Mats and Dan Kärreman (2011b), 'Organizational discourse analysis - well done or too rare? A reply to our critics', Human Relations, 64 (9), $1193-1202$.

Anderson, Ben (2014), Encountering Affect: Capacities, Apparatuses, Conditions, Farnham: Ashgate.

Antaki, Charles, Michael Billig, Derek Edwards and Jonathan Potter (2003), 'Discourse analysis means doing analysis: A critique of six analytic shortcomings', Discourse Analysis Online, 1 (1).

Augoustinos, Martha and Cristian Tileagă (2012), 'Twenty five years of discursive psychology', The British Journal of Social Psychology, 51 (3), 405-412.

Bakhtin, Mikhail M. (1981), The Dialogic Imagination, Austin: University of Texas Press.

Bakhtin, Mikhail M. (1986), Speech, Genres and Other Late Essays, Austin, TX: University of Texas Press.

Bargiela-Chiappini, Francesca (2011), 'Discourse(s), social construction and language practices: In conversation with Alvesson and Kärreman', Human Relations, 64 (9), 1177-1191.

Berger, Peter and Thomas Luckmann (1967), The Social Construction of Reality: A Treatise on the Sociology of Knowledge, Garden City, NY: Anchor Books.

Billig, Michael (1987), Arguing and Thinking: A Rhetorical Approach to Social Psychology, Cambridge: Cambridge University Press.

Billig, Michael (2012), 'Undisciplined beginnings, academic success, and discursive psychology', British Journal of Social Psychology, 51 (3), 413-424.

Burman, Erica (1998), Deconstructing Feminist Psychology, London: Sage.

Burr, Vivien (2003), Social Constructionism (Second Edition), New York: Routledge.

Burr, Vivien (2015), Social Constructionism (Third Edition), New York: Routledge.

Capshew, James H. (1999), Psychologists on the March: Science, Practice and Professional Identity in America, 1929-1969, Cambridge: Cambridge University Press.

Chia, Robert (2000), 'Discourse analysis as organizational analysis', Organization, 7 (3), 513-518.

Chmiel, Nik (2008), An Introduction to Work and Organizational Psychology, Oxford: Wiley/Blackwell.

Chouliaraki, Lilie and Norman Fairclough (2010), 'Critical discourse analysis in organization studies: Towards an integrationist methodology', Journal of Management Studies, 47 (6), 1213-1218.

Deetz, Stanley (2003), 'Reclaiming the legacy of the linguistic turn', Organization, 10 (3), 421-429.

Dickerson, Paul (2012), Social Psychology: Traditional and Critical Perspectives, New York: Pearson Education.

The Editors (2010), 'Critical Discourse Analysis (CDA) in context: Alternative 
perspectives on the analysis of discourse', Journal of Management Studies, 47 (6), 119-21193.

Edwards, Derek (2012), 'Discursive and scientific psychology', British Journal of Social Psychology, 51 (3), 425-435.

Edwards, Derek and Neil Mercer (1987), Common Knowledge: The Development of Understanding in the Classroom, London: Routledge.

Foucault, Michel (1972), The Archaeology of Knowledge, New York: Pantheon.

Foucault, Michel (1980), Power/Knowledge: Selected Interviews and Other Writings 1972-1977, New York: Pantheon.

Foucault, Michel (1984), 'The order of discourse', in Michael Shapiro (ed.), Language and Politics, Oxford, UK: Blackwell, pp. 108-139.

Fox, Dennis and Isaac Prilleltensky (1997), Critical Psychology: An Introduction, London: Sage.

Fox, Dennis, Isaac Prilleltensky and Stephanie Austin (2009), Critical Psychology: An Introduction, London: Sage.

Gergen, Kenneth (1985), 'The social constructionist movement in modern psychology', American Psychologist, 40 (3), 266-275.

Gergen, Mary (2001a), Feminist Reconstructions in Psychology: Narrative, Gender, and Performance, vol. vii, Thousand Oaks, CA: Sage.

Gergen, Mary (2001b), 'The emergence of Feminist Postmodern Psychology', in Mary Gergen (ed.), Feminist Reconstructions in Psychology: Narrative, Gender, and Performance, vol. vii, Thousand Oaks, CA: Sage, pp.9-51.

Gergen, Mary (2010), 'Teaching psychology of gender from a social constructionist standpoint', Psychology of Women Quarterly, 34 (2), 261-264.

Gergen, Mary and Sara N. Davis (1996), Toward a New Psychology of Gender: A Reader, London: Routledge.

Grant, David, Cynthia Hardy, Cliff Oswick and Linda L. Putnam (2004), 'Introduction: Organizational discourse: Exploring the field', in David Grant, Cynthia Hardy, Cliff Oswick and Linda L. Putnam (eds), The Sage Handbook of Organizational Discourse, London: Sage, pp. 1-37.

Hardy, Cynthia and Steve Maguire (2010), 'Discourse, field-configuring events, and change in organizations and institutional fields: Narratives of DDT and the Stockholm Convention', Academy of Management Journal, 53 (6), 1365-1392.

Hardy, Cynthia and Robyn Thomas (2015), 'Discourse in a material world', Journal of Management Studies, 52 (5), 680-696.

Held, Barbara S. (2007), Psychology's Interpretive Turn: The Search for Truth and Agency in Theoretical and Philosophical Psychology, Washington, DC: APA books.

Hepburn, Alexa (2003), An Introduction to Critical Social Psychology, London: Sage.

Hollway, Wendy (1991), Work Psychology and Organizational Behaviour, London: Sage.

Hook, Derek (2007), Foucault, Psychology and the Analytics of Power, Basingstoke: Palgrave Macmillan.

Iedema, Rick (2011), 'Discourse studies in the 21st century: A response to Mats Alvesson and Dan Kärreman's "Decolonializing discourse", Human Relations, 64 (9), 1163-1176.

Illouz, Eva (2007), Cold Intimacies. The Making of Emotional Capitalism, Oxford: Wiley/Blackwell.

Islam, Gazi and Michael Zyphur (2009), 'Concepts and directions in critical 
Industrial/Organizational Psychology', in Dennis Fox, Isaac Prilleltensky and Stephanie Austin (eds), Critical Psychology: An Introduction, London: Sage, pp. 110-125.

Kenny, Kate and Marianna Fotaki (eds) (2014), The Psychosocial and Organization Studies: Affect at Work, New York: Palgrave Macmillan.

Leclercq-Vandelannoitte, Aurélie (2011), 'Organizations as discursive constructions: A Foucauldian approach', Organization Studies, 32 (9), 1247-1271.

Leitch, Shirley and Ian Palmer (2010), 'Analysing texts in context: Current practices and new protocols for critical discourse analysis in organization studies', Journal of Management Studies, 47 (6), 1194-1212.

Mumby, Dennis K. (2011), 'What's cooking in organizational discourse studies? A response to Alvesson and Kärreman', Human Relations, 64 (9), 1147-1161.

Nentwich, Julia (2014), 'Puppen für die Buben und Autos für die Mädchen? Rhetorische Modernisierung in der Kinderkrippe', in Gerlinde Malli and Susanne Sackl-Sharif (ed.), Wider die Gleichheitsrhetorik. Soziologische Analysen - theoretische Interventionen. Texte für Angelika Wetterer, Westfälisches Dampfboot, pp. 50-61.

Oswick, Cliff, David Grant, Robert J. Marshak and Julie Wolfram-Cox (2010), 'Organizational discourse and change: Positions, perspectives, progress and prospects', Journal of Applied Behavioral Science, 46 (1), 8-15.

Parker, Ian (2012), 'Discursive social psychology now', British Journal of Social Psychology, 51 (3), 471-477.

Parker, Ian and Erica Burman (2008), 'Critical psychology: Four theses and seven misconceptions', Hellenic Journal of Psychology, 5, 99-115.

Phillips, Nelson and Maria Laura di Domenico (2009), 'Discourse analysis: Methods and debates', in David Buchanan and Alan Bryman (eds), The Sage Handbook of Organizational Research Methods, London: Sage, pp. 549-565.

Phillips, Nelson and Cliff Oswick (2012), 'Organizational discourse: Domains, debates and directions', Academy of Management Annals, 6 (1), 435-481.

Potter, Jonathan (2012), 'Re-reading Discourse and Social Psychology: Transforming social psychology', British Journal of Social Psychology, 51 (3), 436-455.

Potter, Jonathan and Margaret Wetherell (1987), Discourse and Social Psychology, London: Sage.

Prasad, Pushkala (2005), Crafting Qualitative Research: Working in the Postpositivist Traditions, New York: M.E. Sharpe.

Putnam, Linda (2015), 'Unpacking the dialectic: Alternative views on the discoursemateriality relationship', Journal of Management Studies, 52 (5), 707-716.

Rhodes, Carl (2005), 'Book review of The Sage Handbook of Organizational Discourse', Organization Studies, 26 (5), 793-804.

Steffy, Brian D. and Andrew J. Grimes (1992), 'Personnel/Organizational Psychology: A critique of the discipline', in Mats Alvesson and Hugh Willmott (eds), Critical Management Studies, London: Sage, pp. 181-201.

Steyaert, Chris and Bart Van Looy (2010), Relational Practices, Participative Organizing. Advanced Series in Management Vol. 7, Bingley: Emerald.

Stokoe, Elizabeth, Alexa Hepburn and Charles Antaki (2012), 'Beware the "Loughborough School" of Social Psychology? Interaction and the politics of intervention', British Journal of Social Psychology, 51 (3), 486-496.

Symon, Gillian and Catherine Cassell (2006), 'Neglected perspectives in work and organizational psychology', Journal of Occupational and Organizational Psychology, 79, 307-314. 
Tappan, Mark B. (1997), 'Interpretive psychology: Stories, circles, and understanding lived experience', Journal of Social Issues, 53 (4), 645-656.

Tuffin, Keith (2004), Understanding Social Psychology, London: Sage.

Van Dijk, Teun A. (1997), Discourse as Social Interaction: Discourse Studies Volume II, Newbury Park, CA: Sage.

Van Dijk, Teun A. (2012), 'A note on epistemics and discourse analysis', British Journal of Social Psychology, 51 (3), 478-485.

Weatherall, Ann (2012), 'Discursive psychology and feminism', British Journal of Social Psychology, 51 (3), 463-470.

Wetherell, Margaret (2007), 'A step too far: Discursive psychology, linguistic ethnography and questions of identity', Journal of Sociolinguistics, 11 (5), 661-681.

Wetherell, Margaret (2012), Affect and Emotion: A New Social Science Understanding, London: Sage.

Wilkinson, Sue (1986), Feminist Social Psychology: Developing Theory and Practice, Milton Keynes: Open University Press.

Wilkinson, Sue and Celia Kitzinger (1996), Representing the Other: A Feminism \& Psychology Reader, London: Sage. 